\title{
Gingival and submandibular lymph node metastasis of sigmoid colon adenocarcinoma
}

\author{
J Landeyro ${ }^{1}$, A Raventós ${ }^{1}$, J Mommsen ${ }^{3}$, A Elguezabal ${ }^{1}$, M Gené ${ }^{1}$, L Boutayed ${ }^{1}$, MS Martínez ${ }^{2}$ \\ ${ }^{1}$ M.D., Department of Pathology. Hospital Universitari Joan XXIII . Tarragona. Spain \\ ${ }^{2}$ Ph.D. M.D., Department of Pathology. Hospital Universitari Joan XXIII . Tarragona. Spain \\ ${ }^{3}$ Ph.D. M.D., Department of Maxillofacial Surgery. Hospital Universitari Joan XXIII. Tarragona. Spain
}

Correspondence:

Julieta Landeyro

Department of Pathology

Hospital Universitari Joan XXIII

C/ Mallafrè $i$ Guasch 4

43007 Tarragona, Spain

e-mail julietalandeyro@yahoo.com.ar

Received: 06/01/2009

Accepted: 15/02/2010

\author{
Landeyro J, Raventós A, Mommsen J, Elguezabal A, Gené M, Boutayed \\ L, Martínez MS. Gingival and submandibular lymph node metastasis \\ of sigmoid colon adenocarcinoma. J Clin Exp Dent. 2010;2(1):e47-50. \\ http://www.medicinaoral.com/odo/volumenes/v2i1/jcedv2ilp47.pdf \\ Article Number: $678937 \quad$ http://www.medicinaoral.com/odo/indice.htm \\ (C) Medicina Oral S. L. C.I.F. B 96689336 - eISSN: 1989-5488 \\ eMail: jced@jced.es
}

\begin{abstract}
Introduction: Metastatic tumors of oral and maxillofacial region compromise $1 \%$ of all malignant oral neoplasms. Most commonly affect the jaw bone and less commonly intraoral soft tissues. They originate mainly from primary tumors of lung, breast, colon-rectum, prostate and kidney. Case report: a 77 years old man with history of sigmoid colon adenocarcinoma and liver metastasis. Two years later of being free of disease, he presented with submandibular lymphadenopathy and a gingival mass in right upper jaw. Fine needle aspiration of the node and biopsy of the gingival mass were performed. The cytological smears showed cohesive cell groups on a necrotic background. Biopsy examination showed subepithelial infiltration by neoplasm of glandular pattern with immunoreactivity for keratin 20 and carcinoembryonic antigen. A definitive diagnosis of node and oral metastases of colon adenocarcinoma was made. Discussion: Metastases in the oral and maxillofacial region are very uncommon and usually represent an advanced stage and disseminated disease. They present non specific radiologic and clinical features so it is imperative to reach a definitive diagnosis the cytological/histological examination. Because of its rarity, the diagnosis of metastases in the oral region are a challenging, both to the clinician and to the pathologist, in recognising that a lesion is metastasic and in determining the site of origin.
\end{abstract}

Key words: Gingiva, metastasis, colon adenocarcinoma, nodal metastasis. 


\section{Introduction}

The metastasis of oral and maxillofacial region are rare, compromise $1 \%$ of all oral malignancies (1). They originate from malignant neoplasms of lung, breast, kidney, colon and prostate, and occur more frequently in the jaw bone (2-4). With this presentation, we report a case of an oral (gingival and bone) and submandibular lymph node metastasis of colon adenocarcinoma, and discuss the incidence, clinical features and management of metastatic lesions in this location.

\section{Case Report}

A 77 year old male diagnosed in 2005 in another center of sigmoid colon adenocarcinoma with liver metastases. He was treated with FOLFOX (oxaliplatin-5fluorouracilo-leucovorin) and subsequently underwent surgical resection of hepatic segments V, VI and VII with a good clinical outcome. Two years later being free of disease, he was referred by his dentist to the department of maxillofacial surgery due a gingival tumor of $3 \times 4 \mathrm{~cm}$ in diameter of one month of evolution with no response to antibiotic treatment. The lesion was located at the level of teeth 1.5-2.1 (right upper jaw) and the radiological examination showed the destruction of the outer cortical bone displacing the roots (Fig.1). The rest of the clinical examination, included submandibular lymphadenopathy, painless, firm and slightly adherent to deep tissues of 1 and $1.5 \mathrm{~cm}$ in diameter. Fine needle aspiration (FNA) of one of the nodes and then an incisional biopsy of the gingival lesion were performed. In the cytologic smears were observed a background of abundant necrotic material and three-dimensional groups of cohesive columnar cells with elongated hipercromatic nuclei

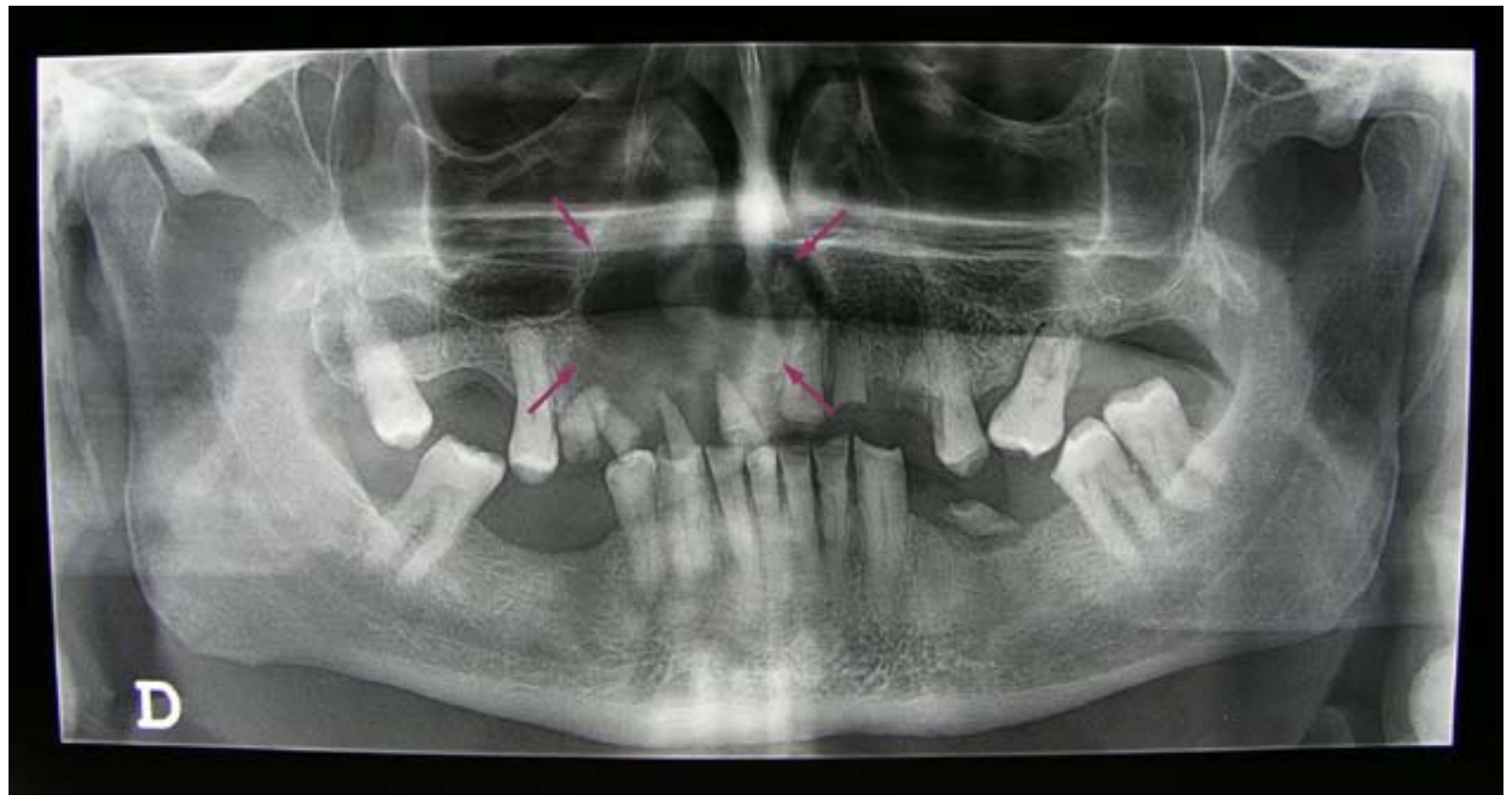

Fig. 1. Orthopantography. Lesion in rigth upper jaw which destroys the outer cortical bone and displaces roots. (arrows)

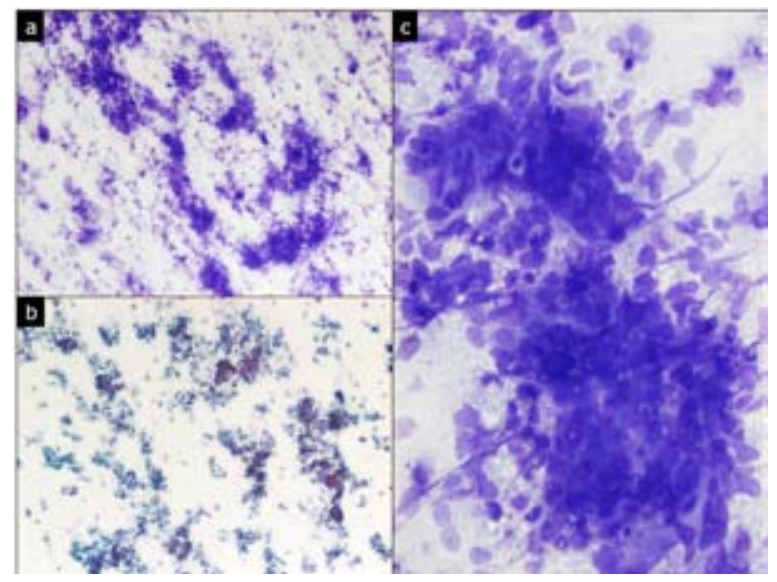

Fig. 2. FNA of submandibular lymphadenopathy. a) and b) necrotic background smear. Diff-Quick and Papanicolau 40x; c) three-dimensional groups of cohesive cells with hipercromatic oval nuclei. Diff-Quick $100 x$

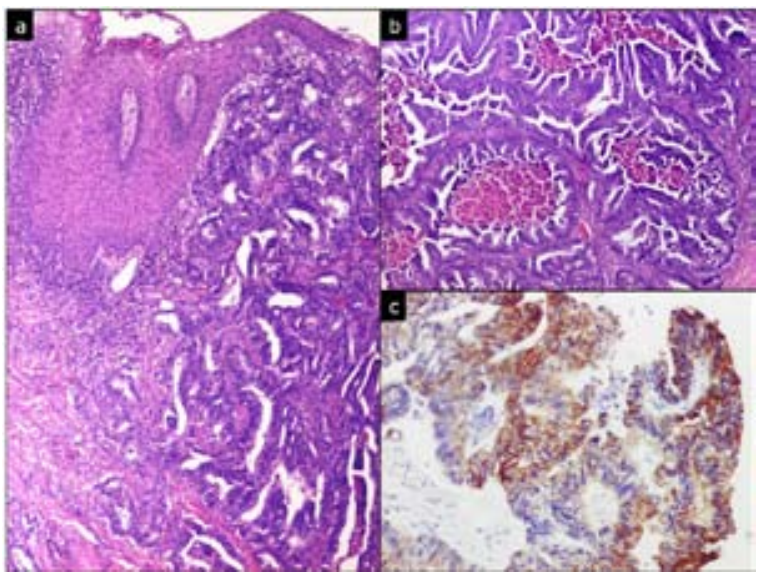

Fig. 3. Gingival tumor biopsy. a) submucosal infiltration by adenocarcinoma. $H \& E 40 x$; b) glandular proliferation with cribriform pattern and central necrosis. $H \& E 40 x$; c) positivity of tumor cells e48 
and ample cytoplasm (Fig. 2). A diagnosis of metastatic carcinoma compatible with nodal metastasis from colon adenocarcinoma was made. The histological examination of the gingival lesion showed surface of squamous epithelium and subepithelial level, an epithelial neoplastic infiltration of cribriform glands lined by columnar cells with elongated nuclei and extensive areas of necrosis. Immunohistochemistry showed positivity of tumor cells to carcinoembryonic antigen (CEA) and keratin 20 (CK20) and negativity to keratin 7 (CK7) (Fig. 3). Final diagnosis was metastatic adenocarcinoma of colon. It is currently unknown patient's clinical course.

\section{Discussion}

The metastasis of oral and maxillofacial region are rare, constituting between $1-3 \%$ of all oral malignancies (1). Occur between the 5 th and 7 th decade of life without sex predilection $(2,5,6)$. The primary neoplasm is known in most cases, but $25 \%$ is the first sign of metastatic disease and between $22 \%$ and $30 \%$ indicates the existence of an unknown primary tumor $(2,5,6)$. The average time between diagnosis of primary tumor and detection of oral metastasis is 40 months, however some may take more than 10 years (5). Most oral metastases are of epithelial origin, although metastatic sarcomas, melanoma and neuroblastoma have been reported (7). The most frequent sites of origin are lung, colo-rectum, kidney and prostate cancer in men and breast, genital tract and kidney in women, tumors more prevalent in the general population $(5,7-10)$. Other sources uncommon are pancreas, thyroid, adrenal gland and liver $(2,5)$.

Bone involvement is the most common presentation of oral and maxillofacial metastasis, most commonly involving the jawbone, and especially the molar region $(5,6)$. The intraoral soft tissue metastases are rare and correspond to $0.1 \%$ of all cancers in the area, the oral mucosa being the most affected site followed by the tongue $(2,3,7)$. Seoane et al. (7) have reported that no prognostic distinction between soft tissue or bone metastasis.

The pathogenesis of oral metastasis is unclear. As the case presented, have also been documented oral metastasis in the absence of lung injury. An explanation for this phenomenon is through Batson's vertebral venous plexus as a mechanism to bypass the lungs, but this hypothesis has not yet been confirmed $(5-7,11)$. In adittion, the jaw bone containing hematopoietic richly vascularized areas that promote early deposition of tumor cells $(2,11)$.

Mandibular bone disease presents clinically with swelling, pain and paresthesias. Gingival involvement causes pain, bleeding, dysphagia or alteration in chewing $(2,5,6,9)$. May also occur as periradicular periodontal disease and in some cases, detected after a tooth extraction, running this procedure as a promoter factor metastatic process.

Radiologically, the mandibular metastases are usually osteolytic lesions and by about $5 \%$ of cases have no radiographic changes $(2,5)$.
The history, location, growth rate, age, sex and radiological findings are often indicative of metastasis but to reach a definitive diagnosis is imperative the cytological/histopatological examination (12). The differential diagnosis of gingival masses should be considered inflammatory, reactives and neoplastic processes. Among benign lesions include: pyogenic granuloma, reparative granuloma of the midline, fibroma, hemangioma and epulis. Among malignant lesions, squamous cell carcinoma of oral cavity versus squamous cell carcinoma of lung, salivary gland ductal carcinoma versus ductal breast carcinoma and primary clear cell tumor of salivary gland versus conventional type renal cell carcinoma $(2,5)$. Some relatively specific immunohistochemical markers can help us to identify the lesion as metastatic and the origin of it, including estrogen and progesterone receptors (breast); androgen receptors and prostate-specific antigen (prostate); CK7 and thyroid transcription factor-1 (lung); CK 20 and CEA (colon - rectum); CD10 and vimentin (kidney). In our case, the morphological and immunohistochemical findings allowed us to recognize as metastatic gingival lesion and determine the site of origin. Considering that this patient already had liver metastases, probably the route of spread was hematogenous and lymph node involvement is secondary to neoplastic infiltration of lymphatic vessels of the area.

The presence of metastases in the oral/maxillofacial region usually represents an advanced stage and multiple-organ disseminated disease with poor prognosis. Most of patients die within the first year of diagnosis with a survival rate at 4 years of $10 \%(3,7)$. The treatment modalities are limited to conservative and palliative therapies intended to improve the quality of life of these patients, and include local resection, radiotherapy or chemotherapy (5).

In conclusion, because of its rarity, the diagnosis of metastatic lesions of the oral and maxillofacial region are a challenge for the clinician to the pathologist. We illustrate with this presentation, a case of oral and nodal metastasis of colon adenocarcinoma and we emphasize that the cytological /histopathological examination is mandatory and with the help of immunohistochemical techniques to determine the origin site.

\section{References}

1. Bodner L, Sion-Vardy N, Geffen DB, Nash M. Metastatic tumors to the jaws: a report of eight new cases. Med Oral Patol Oral Cir Bucal. 2006;11:E132-5.

2. Hirshberg A, Buchner A. Metastatic tumours to the oral region. An overview. Eur J Cancer B Oral Oncol. 1995;31B:355-60.

3. Fukuda M, Miyata M, Okabe K, Sakashita H. A case series of 9 tumors metastatic to the oral and maxillofacial region. J Oral Maxillofac Surg. 2002;60:942-4.

4. van der Waal RI, Buter J, van der Waal I. Oral metastases: report of 24 cases. Br J Oral Maxillofac Surg. 2003;41:3-6.

5. Hirshberg A, Shnaiderman-Shapiro A, Kaplan I, Berger R. Metastatic tumours to the oral cavity - pathogenesis and analysis of 673 cases. Oral Oncol. 2008;44:743-52.

6. Gomes AC, Neto PJ, de Oliveira e Silva ED, Sávio E, Neto IC. Metastatic adenocarcinoma involving several bones of the body and the cranio-maxillofacial region: a case report. J Can Dent Assoc. 2009;75:211-4.

7. Seoane J, Van der Waal I, Van der Waal RI, Cameselle-Teijeiro J, 
Antón I, Tardio A, et al. Metastatic tumours to the oral cavity: a survival study with a special focus on gingival metastases. J Clin Periodontol. 2009;36:488-92.

8. Alvarez-Alvarez C, Iglesias-Rodríguez B, Pazo-Irazu S, DelgadoSánchez-Gracián C. Colonic adenocarcinoma with metastasis to the gingiva. Med Oral Patol Oral Cir Bucal. 2006;11:E85-7.

9. Naylor GD, Auclair PL, Rathbun WA, Hall EH. Metastatic adenocarcinoma of the colon presenting as periradicular periodontal disease: a case report. Oral Surg Oral Med Oral Pathol. 1989;67:162-6.

10. Cama E, Agostino S, Ricci R, Scarano E. A rare case of metastases to the maxillary sinus from sigmoid colon adenocarcinoma. ORL J Otorhinolaryngol Relat Spec. 2002;64:364-7.

11. Shen ML, Kang J, Wen YL, Ying WM, Yi J, Hua CG, et al. Metastatic tumors to the oral and maxillofacial region: a retrospective study of 19 cases in West China and review of the Chinese and English literature. J Oral Maxillofac Surg. 2009;67:718-37.

12. González-Martín-Moro J, Cebrián-Carretero JL, Gómez-García E, del Castillo-Pardo de Vera JL, del Val D. Intraoral tumor with rapid growing. Report of a case. Med Oral Patol Oral Cir Bucal. 2005;10:440-3. 